\title{
Thyroid Gland Papillary Microcarcinoma
}

National Cancer Institute

\section{Source}

National Cancer Institute. Thyroid Gland Papillary Microcarcinoma. NCI Thesaurus. Code C46004.

A papillary carcinoma of the thyroid gland measuring $10 \mathrm{~mm}$ or less in diameter. The survival rates of patients with this type of carcinoma are the same with those of the normal population. 